\title{
Repensar el siglo XIX. Miradas historiográficas desde el siglo $X X$. Por María Luna Argudín, María José Rhi Sausi, coords. México: Secretaría de Cultura, Fondo de Cultura Económica, Universidad Autónoma Metropolitana, 2015, 3І8 p.
}

\author{
Cruz Alberto González Díaz \\ Universidad de Colima \\ gcruzalberto@gmail.com \\ d. \\ DOI: I0.2490I/rehs.v40i157.60I
}

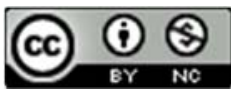

Repensar el siglo XIX. Miradas historiográficas desde el siglo XX. Por María Luna Argudín, María José Rhi Sausi, coords. México: Secretaría de Cultura, Fondo de Cultura Económica, Universidad Autónoma Metropolitana, 2015, 3i8 p. por Cruz Alberto González Díaz se distribuye bajo una Licencia Creative Commons Atribución-NoComercial 4.o Internacional.

El volumen que nos ocupa es producto de varias sesiones de seminario, donde un grupo de historiadores evaluó, con ópticas diversas, las formas en que la república liberal y el Porfiriato fueron representados y construidos en los siglos XX y XXI. Si el lector se deja llevar por la amplitud temporal y temática que el título refiere, se podría pensar que se está ante una obra cuya ambición es diseccionar la forma en que se escribió la historia del siglo XIX occidental o mexicano, desde las corrientes teórico-metodológicas que han dominado la disciplina en el último siglo. Desde el prólogo se nos aclara que el propósito del texto es conocer cómo una época y su historiografía concibieron a la precedente para explicar, comprender e interpretar la conformación de México como nación independiente. El énfasis puesto en los periodos señalados incluye las distintas interpretaciones sobre la construcción, consolidación y cambios del Estado mexicano elaboradas durante el siglo XX y lo que va del XXI por el gremio de los historiadores. Esta preocupación está presente en todos los textos que conforman el volumen.

Las coordinadoras, Luna Argudín y Rhi Sausi, realizan un recuento de la profesionalización de la historia en México durante la primera mitad del siglo XX, señalando el desencanto que sufrieron algunos intelectuales con la Revolución mexicana apenas rebasado el mediodía del siglo, hasta llegar a la ruptura revisionista que ensayó otro tipo de miradas ancladas en el enfoque marxista, después de las turbulencias del año i968 y la década de los setenta. En los ochenta y principios de los noventa, las observaciones emanaron de los entresijos del nacionalismo y la globalización. El proceso estuvo marcado por la internacionalización de la disciplina acaecida entre I960 y I990, y por una aparente despolitización producto de su profesionalización. La 
historia se institucionalizó al producir y asumir normas de conocimiento y prácticas que tendieron a uniformar el discurso del historiador y los géneros en los que se expresa, privilegiando las monografías y los artículos especializados. La difusión del conocimiento, reconocen las autoras, está enfocada a colegas, profesores, investigadores y universitarios. La distancia con el gran público es creciente debido a la especialización, a pesar de los esfuerzos que la comunidad académica ha hecho al confeccionar historias generales, enciclopedias, libros y revistas de divulgación, libros de texto y documentales históricos, a la manera en que los ha popularizado Enrique Krauze. No obstante, la distancia entre el lector y los libros escritos por los historiadores se mantiene y contrasta con el fuerte interés que el primero tiene por leer historia y en cuyo empeño consume biografías e historias noveladas, auténticos best sellersescritos por periodistas y escritores como Francisco Martin Moreno. Se colocan los puntos sobre las íes, al señalar la importancia de la labor del Conacyt en la consolidación de los posgrados y su reciente endurecimiento burocrático que apunta a la mejora de la eficiencia terminal, en detrimento de la calidad y largo aliento de las investigaciones, algo digno de lamentar a pesar de que con ello se privilegie indirectamente la escritura de artículos de investigación. Se apunta también la falta de capacidad de las universidades y centros de investigación para insertar a los historiadores recién egresados de los posgrados y para renovar a los que poseen contratos temporales, lo que ha redundado en el envejecimiento de las plantas académicas. Finalmente, las coordinadoras advierten sobre los melifluos cantos de sirena de los rankingsinternacionales, los mismos que con estrategias ajenas a la naturaleza de la disciplina, pregonan y presionan la publicación en inglés para medir la calidad en términos de visibilidad e impacto.

Los autores de los textos, que conforman el volumen, coinciden en una apreciación paradójica: en México, el desarrollo de la historia estuvo vinculado a políticas estatales que ofrecieron el soporte material y a la creciente autonomía de la academia frente a los círculos de poder. No obstante haberse acotado al análisis de los trabajos historiográficos emblemáticos que problematizaron aspectos del Porfiriato y la Reforma durante el siglo XX, las miradas de los investigadores perciben deconstrucciones y dejan ver autores, conceptos y modalidades de la disciplina que determinan su mirada. Se cita, con cierta prolijidad, a Charles Hale, a Marcello Carmagnani y a François-Xavier Guerra, invocando también, el giro interpretativo de la historia cultural; se utilizan los instrumentos estadísticos de los que se ha apropiado la historia económica y se develan las batallas entre la historiografía francesa y estadounidense acaecidas en el pensamiento historiográfico mexicano, lo que reflejaría la primacía de la segunda sobre la primera, al menos entre los cultores de la historia social.

La obra se inscribe dentro de los límites del análisis historiográfico y la teoría de la historia y su lectura puede ser aprovechada por los investigadores y estudiantes abocados a los periodos aquí mencionados. Es también un buen ejemplo de lo que los académicos hacemos hoy día: escribimos para nuestros pares y estudiantes y estamos lejos del gran público, debido a la especialización de la disciplina. La distancia entre el lector y los libros escritos por los historiadores se mantiene y es llenada por biografías e historias noveladas confeccionadas por escritores improvisados que, no obstante, logran conectar con el público de una forma que los historiadores profesionales pocas veces logran. 
Una de las fortalezas del texto, aunque también una de las razones que no hace condescendiente su lectura, es que no está abocado, como otros trabajos de análisis historiográfico, al acercamiento de un autor y una obra en cada uno de los ensayos que lo componen. ${ }^{ \pm}$Los autores realizan una lectura y un análisis de varios de los historiadores implicados en el periodo de su interés, es por eso que tenemos noticias de obras y personajes tales como México: su evolución social (Justo Sierra); Juárez y las Revoluciones de Ayutla y Reforma (Francisco Bulnes); La constitución de 1857 y sus críticos e Historia moderna de México (Daniel Cosío Villegas); El liberalismo mexicano (Jesús Reyes Heroles); La supervivencia política novohispana (Edmundo O' Gorman); Historia económica y social de México (Luis Chávez Orozco); Historia de la nación mexicana (Mariano Cuevas); Historia de México (José Bravo Ugarte); así como de la tetratología de José Fuentes Mares sobre Juárez y la obra insignia de Luis González y González (Pueblo en vilo). Una de las particularidades de la obra, es que, si bien está enfocada a los libros que tocan aspectos sobre la Reforma y el Porfiriato elaborados por los historiadores y estudiosos del siglo XX, permite a su vez, conocer los enfoques positivista, historicista, marxista, liberal, católico y hermenéutico que en ellos fueron utilizados.

Notas

I Cfr. Evelia Trejo y Álvaro Matute, eds., Escribir la historia en el siglo XX. Treinta lecturas (México: Universidad Nacional Autónoma de México, 2009). 